\title{
0012 CREATING A SAFE COMMUNITY THROUGH THE WALK THIS WAY PROGRAM: SAFE KIDS PHILIPPINES EXPERIENCE
}

A C Rolloque*, R Consunji, M M Alcantara, M T A Perez, J Rolloque Correspondence: Safe Kids Philippines, 3/F Cargohaus Bldg. Brgy. Vitales NAIA Complex, Paranaque City 1700, Philippines

10.1136/ip.2010.029215.12

Objective To lessen and create awareness on children and their families on road traffic injuries. Be safe and be empowered in developing interventions that will lessen road traffic injuries in their communities.

Methods Safe Kids Philippines developed a Walk This Way, a pedestrian safety program to teach safe behaviour to children, parents, motorists and create safer, more walkable communities. The organisation organised stakeholders meetings and involved people from the communities such as Barangay officials, government and non-government organisations. Side by side children attended classroom teachings on road safety conducted by volunteers. The Three Es were used such as Education, Engineering and Enforcement to empower the children and their families. Aside from that national events were conducted to reinforce the learnings of children on road safety.

Results The organization was able to organize people from local to the national level and involve them to road safety education. Children from 89 Public Elementary Schools started to teach their siblings and their families on road safety situation in the country. They became aware on road safety and practiced it. They put traffic enforcers where they are needed, put road signs and organised crosswalk paintings. But most of all the National Injury Prevention Program was organized.

Discussion It can be concluded that road traffic injuries can be prevented; safe and equitable communities are possible if interventions are developed. The involvement of other stakeholders is a key component on the effectiveness of the program. 